\title{
The prevalence of low vision and blindness in a Canadian inner city
}

${ }^{1}$ Department of Ophthalmology, University of British Columbia, Vancouver, BC, Canada

${ }^{2}$ Faculty of Medicine, University of British Columbia, Vancouver, BC, Canada

${ }^{3}$ Department of Family Practice, University of British Columbia, Vancouver, BC, Canada

${ }^{4}$ Vancouver Native Health Society Clinic, Vancouver, BC, Canada

Correspondence:

DAL Maberley,

Department of Ophthalmology, University of British Columbia, 2550

Willow Street,

Vancouver, BC,

Canada V5Z 3N9

Tel: + 1604875 4599;

Fax: + 16048754699

E-mail: crtg_vancouver@ hotmail.com

Received: 11 September 2005

Accepted in revised form: 29 November 2005

Published online: 3 February 2006

Meeting Presentation: Canadian Ophthalmology Society Meeting; Halifax, NS 2004

Financial Support: University of British Columbia,

Strategic Teaching Initiative Conflict of Interest: None

\begin{abstract}
Purpose To ascertain the prevalence and primary causes of visual impairment in a sample of patients from Vancouver's downtown eastside (VDES).

Materials and methods A total of 200 patients seeking nonophthalmic medical care at the Vancouver Native Health Society (VNHS) clinic in Vancouver's inner city (downtown eastside) participated in this observational case-series study. For each participant, we obtained demographic information, a medical and ocular history, and performed a complete eye exam. The prevalence of visual disability using standard North American criteria was reported. Causes of visual loss were also reported based on Canadian National Institute for the Blind (CNIB) guidelines.

Results A total of 200 patients participated in our study. The median age of our sample was 46 years, $69 \%$ were male. There were very high rates of comorbid medical conditions including HIV, Hepatitis B/C, IV drug use, and diabetes. The raw prevalence of visual disability based on best-corrected visual acuity (BCVA) was 500 per 10000 ; this was over nine times greater than in the general Canadian population. The raw prevalence rate of 'presenting visual disability' based on presenting visual acuity (PVA) was 2400 per 10000. Major causes of visual disability were cataract and retinal disease. Although agerelated macular degeneration and diabetic retinopathy represent major causes of vision loss in North America, no cases were noted in our sample.

Conclusion The overall prevalence of visual disability was alarmingly high in this disadvantaged community. These results identify both ophthalmic disease and access to refraction and prescription spectacles as a significant health concern among people living in the VDES.
\end{abstract}

DAL Maberley', H Hollands², A Chang', S Adilman ${ }^{3}$, B Chakraborti ${ }^{4}$ and G Kliever $^{4}$

Eye (2007) 21, 528-533. doi:10.1038/sj.eye.6702257; published online 3 February 2006

Keywords: visual disability; visual impairment; marginalized populations; prevalence; Vancouver's downtown eastside

\section{Introduction}

Little is known about the prevalence of eye disease among the inner-city poor, homeless, and under-housed in Canada. We know that socioeconomic status is one the major predictors of general health and suspect a link with eye disease as well; however, few studies have specifically sought to evaluate the prevalence of visual disability in a disadvantaged inner-city population. ${ }^{1}$ There is evidence from the United States to suggest that economically disadvantaged individuals are more likely to have glaucoma and cataract than the general population. ${ }^{2,3}$ However, studies of this nature cannot be applied directly to Canadian marginalized populations given the differences in welfare and health care structures.

Medical care and research involving the homeless, under-housed, and the marginalized are complicated because of the relative geographic and psychological isolation that these people experience. ${ }^{4}$ In addition, previous negative experiences with the health care system may disengage them from traditional medical care. Efforts are needed to evaluate the health status of inner-city populations in the context of their own environment. Following this, measures may be considered to improve the quality, quantity, and accessibility of health care for this segment of our society.

Vancouver's downtown eastside (VDES) has an estimated population of 16000 and is the home to about 5000 injection drug users. 5,6 This neighbourhood is the poorest in Canada with a transient population of homeless and 
under-housed individuals. The community is diverse and consists of many people who are mentally ill, homeless, sex trade workers, immigrants, troubled youth, and First Nations people. This community is experiencing an epidemic of HIV/AIDS, hepatitis, tuberculosis, and syphilis and has among the highest HIV infection rates of any community in the Western World. ${ }^{6,7}$

All of the main health concerns of VDES residents have potential ocular complications. Intravenous drug abuse, sexually transmitted disease, HIV/AIDS, hepatitis, and diabetes are all prevalent in this population and have serious ocular sequellae that can lead to vision loss and functional impairment. The importance of eye health in this population relates to the fact that ocular function is highly correlated with general functional levels and, as such, is essential for independence-especially in an environment as challenging as VDES.

Our goal with the present study was to evaluate the prevalence of visual disability and causes of vision loss in an inner-city population from VDES. Firstly, we wanted to estimate the prevalence of visual disability according to accepted standards used in North America based on best-corrected visual acuity (BCVA). In addition, since this population has many problems accessing health care (including refractive eye care) we also wanted to estimate the prevalence of 'presenting visual disability' - defined using visual acuity measurements taken with each patient's current refractive glasses or contact lenses (presenting visual acuity (PVA)). Finally, we sought to determine the primary causes of visual disability in this population.

\section{Materials and methods}

The Vancouver Native Health Society (VNHS) is a nonprofit organization located in VDES. The medical clinic operated by the society was established in 1991 . The VNHS is one of three main clinics providing medical care in this neighbourhood. It provides general medical services to over 12000 people per year and has an established reputation as a safe place to receive these services. Patients do not require a valid provincial health card to receive medical services at the VNHS. Despite the 'native' designation in the VNHS name, the physicians and nurses at this clinic serve all members of the VDES population and attendees are representative of the ethnicity of the larger community.

At the time of this study, eye examinations were not part of the routine medical care available at the VNHS. All study participants had presented to the VNHS for nonocular health issues including, general medical care, alcohol and drug counseling, diabetes education, dietary consultation, high-risk pregnancy care, or other educational programs. Consecutive individuals presenting to the clinic during weekly $2 \mathrm{~h}$ intake sessions between 2001 and 2002 were approached by a clinic nurse and were offered participation in the study. The University of British Columbia's Medical Ethics board approved the research protocol and all participants signed an informed consent.

Initially, a nurse obtained relevant demographic and medical history through a standardized interview. Demographic variables obtained included: age, gender, marital status, level of education, and employment/ social assistance status. Self-reported medical histories of chronic diseases as well as a relevant ocular histories were sought. Finally, a full ocular examination was conducted by an ophthalmologist. This assessment included a PVA using patients' present refractive devices, a BCVA, pupil evaluation, confrontation fields, slit-lamp examination, and a dilated retinal examination.

The cause of vision loss for each eye with reduced vision was recorded, and visual disability was classified according to the cause of vision-loss in the better-seeing eye. If there was more than one potential cause of vision loss in the better-seeing eye, the primary reason for the visual loss was left to the evaluating ophthalmologist's discretion. The cause of visual loss was categorized into one of nine groupings based on Canadian National Institute of the Blind (CNIB) definitions.

Visual disability was categorized using the North American definition based on the BCVA in the better seeing eye. 'Not-impaired' was defined as BCVA better than or equal to $20 / 40$, 'low vision' as worse than $20 / 40$ but better than 20/200, and 'blind' was defined as 20/200 or worse. Visual disability included those patients, who were classified as low vision or as blind. In addition, we reported 'presenting visual disability' using PVA.

Confidence intervals were calculated for the raw prevalence data using the exact method. ${ }^{8}$ This data was also directly age-standardized to the Canadian population using the 2001 Census data. ${ }^{8,9}$

\section{Results}

Data were collected on 200 eligible patients. A total of 137 patients $(68.5 \%)$ were male. The mean and median age were 46 years and ages ranged from 15 to 81 years. The majority of eligible participants were unemployed, single, high school educated, and either Caucasian or Native Indian. Table 1 shows an overview of the demographic characteristics of the population. The study participation rate was over $90 \%$ as routine eye examinations were deinsured in Vancouver at the time (making refractions and eye examinations difficult to obtain in the community). 
Table 1 Demographic characteristics of sample

\begin{tabular}{|c|c|c|}
\hline & Number & Percentage \\
\hline \multicolumn{3}{|l|}{ Sex } \\
\hline Male & 137 & 68.5 \\
\hline \multicolumn{3}{|l|}{ Age (years) } \\
\hline $0-29$ & 10 & 5.0 \\
\hline $30-39$ & 47 & 23.5 \\
\hline $0-49$ & 77 & 38.5 \\
\hline $50-59$ & 48 & 24.0 \\
\hline $60+$ & 18 & 9.0 \\
\hline \multicolumn{3}{|l|}{ Marital status } \\
\hline Single & 126 & 63.0 \\
\hline Married/common-law & 31 & 15.5 \\
\hline Divorced/separated & 42 & 21.0 \\
\hline \multicolumn{3}{|l|}{ Highest education achieved } \\
\hline Elementary school & 18 & 9.0 \\
\hline Junior high school & 46 & 23.0 \\
\hline High school (no graduation) & 57 & 28.5 \\
\hline High school graduation & 79 & 39.5 \\
\hline \multicolumn{3}{|l|}{ Some college education } \\
\hline Yes & 35 & 17.5 \\
\hline \multicolumn{3}{|l|}{ Employment status } \\
\hline Employed/unemployment insurance & 16 & 8.0 \\
\hline Social assistance & 88 & 44.0 \\
\hline Disability (type1) & 10 & 5.0 \\
\hline Disability (type2) & 64 & 32.0 \\
\hline Old-age pension & 7 & 3.5 \\
\hline Unknown & 15 & \\
\hline \multicolumn{3}{|l|}{ Ethnicity } \\
\hline Caucasian & 95 & 47.5 \\
\hline First nations & 83 & 41.5 \\
\hline Other & 22 & 11.0 \\
\hline
\end{tabular}

The patients in our sample had many common, serious health concerns including intravenous drug use and $\mathrm{HIV} /$ hepatitis B and C positivity. Table 2 shows an overview of the self-reported comorbid conditions in our sample.

Table 3 shows the ocular data for the sample. A total of 10 patients were visually disabled (two were blind, eight had low vision) according to strict North American definitions based on BCVA. The nonstandardized prevalence of visual disability (based on BCVA) within our sample was 500 per 10000 (95\% confidence interval (CI): 242-900 per 10000). The nonstandardized prevalence of low vision and blindness were 400 per 10000 (95\% CI: 174-770 per 10000) and 100 per 10000 (95\% CI: 12-356 per 10000), respectively.

Using the 'presenting visual acuity' definition, we found 48 participants were effectively visually disabled (14 were blind, 34 had low vision). The nonstandardized
Table 2 Medical comorbidities of the sample ${ }^{\mathrm{a}}$

\begin{tabular}{lcc}
\hline Self-reported comorbidities & Number & Percentage \\
\hline HIV & 63 & 31.5 \\
IV drug use & 46 & 23.0 \\
Hepatitis B/C & 33 & 16.5 \\
Other illicit drugs (not IV) & 30 & 15.0 \\
Diabetes mellitus & 25 & 12.5 \\
Alcohol & 19 & 9.5 \\
Heart disease & 14 & 7.0 \\
Asthma & 12 & 6.0 \\
Schizophrenia & 11 & 5.5 \\
Hypertension & 8 & 4.0 \\
Depression & 8 & 4.0 \\
Osteoarthritis & 7 & 3.5 \\
Tuberculosis & 7 & 3.5 \\
Atrial fibrillation & 5 & 2.5 \\
Other comorbidities & 55 & 27.5 \\
\hline
\end{tabular}

${ }^{a} n=200$.

Table 3 Vision related data ${ }^{\mathrm{a}}$

\begin{tabular}{|c|c|c|}
\hline & Number & Percentage \\
\hline \multicolumn{3}{|c|}{ Presenting visual acuity (PVA) in better-seeing eye } \\
\hline $20 / 20$ or better & 71 & 35.5 \\
\hline $20 / 25-20 / 30$ & 68 & 34.0 \\
\hline $20 / 40-20 / 100$ & 47 & 23.5 \\
\hline $20 / 200-20 / 400$ & 11 & 5.5 \\
\hline CF or worse & 3 & 1.5 \\
\hline \multicolumn{3}{|c|}{ Classification of presenting visual disability (based on PVA) } \\
\hline Not impaired & 152 & 76.0 \\
\hline Low vision & 34 & 17.0 \\
\hline Blind & 14 & 7.0 \\
\hline \multicolumn{3}{|c|}{ Best-corrected vision (BCVA) in better-seeing eye } \\
\hline $20 / 20$ or better & 137 & 68.5 \\
\hline $20 / 25-20 / 30$ & 49 & 24.5 \\
\hline $20 / 40-20 / 100$ & 12 & 6.0 \\
\hline $20 / 200-20 / 400$ & 1 & 0.5 \\
\hline CF or worse & 1 & 0.5 \\
\hline \multicolumn{3}{|c|}{ North American classification of visual disability (based on BCVA } \\
\hline Not impaired & 190 & 95.0 \\
\hline Low vision & 8 & 4.0 \\
\hline Blind & 2 & 1.0 \\
\hline
\end{tabular}

prevalence of 'presenting visual disability' within our sample was 2400 per 10000 (95\% CI: 1825-3053 per $10000)$. The nonstandardized prevalence of 'presenting low vision and blindness' were 1700 per 10000 (95\% CI: $1206-2293$ per 10000) and 700 per 10000 (95\% CI: 387-1146 per 10000 , respectively).

The VDES population we evaluated was an older population than the Canadian median, based on the 2001 national census (46 years vs 39 years), and the distribution of ages was quite different than the 
Canadian population (see Table 4). Specifically, most of our subjects were clustered around the median age (46 years). Our sample had no children $<15$ years old, and few teenagers, young adults, or elderly persons.

Table 5 shows the prevalence of visual disability based on BCVA and PVA among the different age groupings in our sample. Table 5 also compares raw prevalence rates to published rates found by us in a representative Canadian city. ${ }^{10}$ The raw rate of visual disability based on BCVA in the VDES population was 9.2 times higher than the Canadian rate.

The age-standardized prevalence of visual disability found by us previously in a representative Canadian city was 94.8 per 10000 . The age-standardized prevalence of visual disability based on BCVA in this sample was 568 per 10000 . The age-standardized prevalence of low

Table 4 Age distribution of study sample and comparison to the Canadian population

\begin{tabular}{|c|c|c|c|}
\hline \multirow[t]{2}{*}{$\begin{array}{l}\text { Age } \\
\text { groups }\end{array}$} & \multicolumn{2}{|c|}{$\begin{array}{l}\text { Study sample } \\
\quad(\mathrm{n}=200)\end{array}$} & \multirow{2}{*}{$\begin{array}{c}\text { Canadian population } \\
\text { comparison (>age } 14 \\
\%\end{array}$} \\
\hline & No & $\%$ & \\
\hline 15-19 & 1 & 0.5 & 8.5 \\
\hline $20-24$ & 3 & 1.5 & 8.1 \\
\hline $25-44$ & 93 & 46.5 & 37.5 \\
\hline $45-54$ & 66 & 33.0 & 18.2 \\
\hline 55-64 & 28 & 14.0 & 11.8 \\
\hline $65-74$ & 7 & 3.5 & 8.8 \\
\hline 75-84 & 2 & 1.0 & 5.5 \\
\hline $85+$ & 0 & 0 & 1.7 \\
\hline Total & 200 & 100 & 100 \\
\hline
\end{tabular}

${ }^{\mathrm{a} C a n a d i a n} 2001$ National Census data (statscan.ca). vision and blindness based on BCVA in our sample were 512 per 10000 and 56 per 10000 , respectively. The agestandardized prevalence of visual disability based on PVA in our sample was 2515 per 10000 . The agestandardized prevalence of low vision and blindness based on PVA in our sample was 2095 per 10000 and 419 per 10000 , respectively.

The causes of visual loss among those patients with visual disability are shown in Table 6 along with a comparison to the general population. Cataract accounted for half of the visual disability (based on BCVA) in our VDES sample and 'other retinal diseases' accounted for twenty percent. Age-related macular

Table 6 Causes of visual loss of patients in our sample and a comparison to causes of visual loss in a representative Canadian population

\begin{tabular}{|c|c|c|c|c|}
\hline \multirow[t]{2}{*}{$\begin{array}{l}\text { Primary cause } \\
\text { of visual loss }\end{array}$} & \multicolumn{2}{|c|}{$\begin{array}{l}\text { Visually disabled }^{\mathrm{a}} \\
\text { based on BCVA } \\
\quad(\mathrm{n}=10)\end{array}$} & \multicolumn{2}{|c|}{$\begin{array}{l}\text { Proportion of visually } \\
\text { disable in Canadian } \\
\text { comparison }(\mathrm{n}=40)^{\mathrm{b}}\end{array}$} \\
\hline & No. & $\%$ & No. & $\%$ \\
\hline $\begin{array}{l}\text { Age-related macular } \\
\text { degeneration (ARMD) }\end{array}$ & & & 7 & 17.5 \\
\hline Diabetic retinopathy & & & 3 & 7.5 \\
\hline Other retinal cause & 2 & 20.0 & 7 & 17.5 \\
\hline Glaucoma & & & 3 & 7.5 \\
\hline Visual pathway & & & 6 & 15.0 \\
\hline Cataract & 5 & 50.0 & 7 & 17.5 \\
\hline Cornea/conjunctiva & 1 & 10.0 & 2 & 5.0 \\
\hline Refractive error & & & 2 & 5.0 \\
\hline Other (iris, trauma, lid) & 1 & 10.0 & 3 & 7.5 \\
\hline Normal eye exam & 1 & 10.0 & & \\
\hline
\end{tabular}

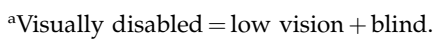

${ }^{b}$ Maberley et al. 2005, Eye, in press. ( $>15$ years old only, $n=40$, based on best-corrected visual acuity).

Table 5 Age-specific prevalence rates of visual disability in our sample and in a representative Canadian sample

\begin{tabular}{|c|c|c|c|c|c|c|}
\hline \multirow[t]{2}{*}{ Age groups } & \multicolumn{2}{|c|}{$\begin{array}{l}\text { Visually disability based on PVA } \\
\text { in sample }(\mathrm{n}=48)\end{array}$} & \multicolumn{2}{|c|}{$\begin{array}{l}\text { Visually disability }{ }^{\mathrm{a}} \text { based BCVA } \\
\text { in sample }(\mathrm{n}=10)\end{array}$} & \multicolumn{2}{|c|}{$\begin{array}{l}\text { Visually disabled in representative } \\
\text { Canadian sample (Prince George, } B C)^{\mathrm{t}}\end{array}$} \\
\hline & No & $\begin{array}{l}\text { Raw prevalence } \\
\text { (per } 10000)\end{array}$ & No & $\begin{array}{l}\text { Raw prevalence } \\
\text { (per } 10000)\end{array}$ & No & $\begin{array}{l}\text { Raw prevalence } \\
\text { (per } 10000)\end{array}$ \\
\hline 15-19 & 1 & 10000 & 0 & 0 & 1 & 15 \\
\hline $20-24$ & 0 & 0 & 0 & 0 & 1 & 18 \\
\hline $25-44$ & 25 & 2688 & 3 & 323 & 3 & 12 \\
\hline $45-54$ & 15 & 2273 & 2 & 303 & 2 & 16 \\
\hline $55-64$ & 4 & 1429 & 3 & 1071 & 0 & 0 \\
\hline $65-74$ & 1 & 1429 & 1 & 1429 & 10 & 262 \\
\hline $75-84$ & 2 & 10000 & 1 & 5000 & 15 & 892 \\
\hline $85+$ & 0 & 0 & 0 & 0 & 8 & 1807 \\
\hline Total & 48 & 2400 & 10 & 500 & 40 & 54 \\
\hline
\end{tabular}

aisually disabled $=$ low vision + blind.

${ }^{b}$ Maberley et al., 2005, Eye, in press. ( $>15$ years old only, $n=40$, based on best-corrected visual acuity). 
degeneration did not account for any visual loss causing visual disability in our sample, but accounted for one quarter of the cases in the Canadian sample.

\section{Discussion}

We estimate the prevalence of visual disability based on BCVA in the VDES community to be 500 per 10000 ; over nine times more than the estimated Canadian rate. We have also estimated the prevalence of 'presenting visual disability' among the VDES community to be 2400 per 10000 , or almost one quarter of the population. This increase in prevalence is due to refractive error over and above the causes of visual disability that could not be improved with a pinhole or refraction. Although this 'presenting visual disability' would be of little concern in most communities, it is of specific importance among this population since acquiring and maintaining spectacles or contact lenses in the VDES environment is particularly difficult. These results identify both ophthalmic disease and access to refractive care as significant health issues among people living in the VDES.

To our knowledge no previous Canadian study has provided prevalence data on low vision and blindness in a marginalized inner-city population. However, results similar to these have been shown in other communities with limited access to eye care. For example, Barbadosborn citizens in the United States who reported their race as black had a prevalence of low vision based on World Health Organization criteria of $5.9 \% .^{11}$ In addition, it has been reported that aboriginals in Australia have up to a 10 times higher prevalence of blindness compared to nonaboriginals. ${ }^{12}$

We suspect there are two reasons for higher rates of eye disease in our study population. First, our sample has high rates of comorbid disease and life-style risk factors for poor health including HIV, Hepatitis B/C, alcohol and intravenous drug abuse. Many of these systemic diseases can lead to ocular pathology (eg HIV) while life-style risk factors such as intravenous drug use can also predispose patients to ocular disease. Second, barriers to accessing health care in the VDES are manifold, including: under-availability of specialists in the neighbourhood, transportation difficulties, the lack of fixed addresses for patient contact, anxiety about attending tertiary health care facilities, etc.

The specific causes of vision loss identified within our VDES sample are not in keeping with the common diagnoses from prior Canadian prevalence study conducted in representative medium-sized workingclass city (Prince George, BC). Interestingly, cataract accounted for half of the visual disability in our sample compared to only $18 \%$ in the Canadian sample. We speculate that the referral process and preoperative testing requirements (along with the barriers noted above) may hinder access to surgery for these individuals.

In addition, age-related macular degeneration (AMD) and diabetic retinopathy account for one-quarter of the adult cases of visual disability in Canada, but did not result in any cases of visual disability among the VDES participants. This may be because there were very few older individuals in our sample (see Table 4) due to an increased mortality among VDES residents due to comorbid conditions. AMD is a disease justifiably associated with age whereas visual disability due to diabetes is a late-stage complication of the disease.

Eye care in Canada is typically administered in the community setting and, as such, prevalence evaluations of blindness and low vision cannot be gleaned from provincial, hospital, or institutional databases. To ensure precise clinical diagnoses, best-corrected visual acuities, and visual field data for our prevalence evaluation (in the absence of a large population-based study) we believed it was essential to actually conduct complete ophthalmic evaluations ourselves. However, our sampling methodology may be faulted as it is likely to include individuals who are more likely to have systemic medical conditions that could predispose them to eye pathology. Also individuals who are house-bound or who do not seek medical care would not be included in our patient population.

In conclusion, this is the first paper to estimate the prevalence of visual disability in an inner-city Canadian population using accurate diagnostic and visual acuity data. Rates of visual disability due to nonrefractive eye pathology are up to nine times higher than the general Canadian population. In addition, close to one quarter of those sampled may have a visual disability due to refractive error that is not corrected in this real-world setting (PVA). Eye health and refractive care pose a major public health concern for this inner-city community and efforts need to be directed towards improving eye care services for this and similar populations.

\section{References}

1 Hameed TK, Hodge WG, Buhrmann R. An inventory of information on blindness and visual impairment in Canada. Can J Ophthalmol 2001; 36: 175-185.

2 Ho JH, Chang RJ, Wheeler NC, Lee DA. Ophthalmic disorders among the homeless and nonhomeless in Los Angeles. J Am Optom Assoc 1997; 68(9): 567-573.

3 Tielsch JM, Sommer A, Witt K, Katz J, Royall RM. Blindness and visual impairment in an American Urban population. The Baltimore Eye Survey. Arch Ophthalmol 1990; 108: 286-290.

4 Strathdee S, Archibald C, Patrick DM, Strathdee SA, Archibald CP, Ofner M et al. Determinants of HIV 
seroconversion in IDUs during a period of rising prevalence in Vancouver. Int J AIDS and STD 1997; 8: 427-435.

5 City of Vancouver. Dowtown Eastside Community Monitoring Report. Vancouver, 1999; 1.

6 Schecter M, O'Shaughnessy M. Distribution of Injection Drug Users in the Lower Mainland. A brief report for the Vancovuer/Richmond Health Board, 1999; 33; p. 6-22.

7 Tyndall MW, Craib KJ, Currie S, Li K, O'Shaughnessy MV, Schechter MT. Impact of HIV infection on mortality in a cohort of injection drug users. J Acquired Immune Deficiency Syndrome 2001; 28(4): 351-357.

8 Rosner B. Fundamentals of Biostatistics, 4th ed. Duxbury: Toronto.
9 www.statscan.ca.

10 Maberley DAL, Hollands H, Chuo J, Tam G, Konkal J, Roesch $\mathrm{M}$ et al. The prevalence of low vision and blindness in Canada. Eye 2005; advance online publication, May 20; doi:10.1038/sj/eye.6701879.

11 Rahmani B, Tielsch JM, Katz J, Gottsch J, Quiglley H, Javittt J et al. The cause-specific prevalence of visual impairment in an urban population. The Baltimore Eye Survey. Ophthalmology 1996; 103(11): 1721-1726.

12 Taylor H. Eye Health in Aboriginal and Torres Strait Islander Communities. Report for the Commonwealth minister of Health and Family Services Canberra, ACT, AGPS: Australia, 1997. 